\title{
Prevalence of Pre-Menstrual Syndrome in Young Girls
}

\author{
N AKMAL N AKHTAR GERAANA R ATTIQUE \\ Department of Obstetrics \& Gynaecology, Sir Ganga Ram Hospital/Fatima Jinnah Medical College, Lahore \\ Correspondence to Dr. Noreen Akmal, Assistant Professor EMAIL:- noreenakmal@hotmail.com
}

\begin{abstract}
Prevalence of pre-menstrual syndrome(PMS) was determined in 100 girls in age group 16-22 years, belonging to a medical college. Ou of total $66.66 \%$ had PMS. Major complaints were aches \& pains, pre-menstrual dysmenorrhoea and mood swings.
\end{abstract}

Key Words: Pre-menstrual syndrome, pre-menstrual dysmenorrhoea.

PMS is a recurring cyclic disorders in the luteal phase of menstrual cycle involving behavioral, psychological and physical changes resulting in loss of work or social impairemement ${ }^{1}$. Reported prevalence of PMS ranges from $1 \%$ to $90 \%^{2}$. Symptoms of PMS are varied and nonspecific, broadly classified as physical, psychological and behavioral symptoms. Common physical symptoms are breast tenderness and swelling, bloating, oedema and weight gain. Psychological symptoms include depression, tension, irritability, anxiety, tiredness, loss of libido, disturbed sleeping and eating patterns. The behavioral changes include absenteeism from work and decrease in cognitive function ${ }^{3}$. The precise pathophysiology of PMS is still unknown, but it is believed that it is due to altered equilibrium between sex steroids and central neuro transmitters ${ }^{4}$.

This study was conducted to find out the frequency of symptoms of PMS in young girls.

\section{Patients and Methods:}

A total of 150 girls were included in the study. Purposive sampling was applied to select 100 girls between 16-22 years of age, among the students of Fatima Jinnah Medical College \& Nursing School of Sir Ganga Ram Hospital. Girls with history of some medical and psychological disorders were not inciuded in the study.. A specially designed questionnaire which included patients particulars \& symptoms of PMS under three major headings i.e. physical, psychological, and behavioral symptoms was given to these girls. Questionnaire was filled at the spot after explaining, taking consent Statistical Analysis was done by use of SPSS version 10. It was computer based analysis of frequency and percentage.

\section{Results:}

This observational study was conducted on 150 giris in age group of 16-22 years. Out of these 100 girls showed some symptoms of PMS thus giving a frequency of $66.66 \%$. Table I shows frequency distribution of various physical symptoms, aches and pain (58\%) and dysmenorrhoea $(56 \%)$ were the most common physical symptoms.
Table I Frequency of Physical Symptoms $(n=100)$

\begin{tabular}{lcc}
\hline Symptoms & $\mathrm{n}$ & \%age \\
\hline Breast Tenderness & 36 & 36 \\
Weight Gain & 29 & 29 \\
Change in Bowel Habits & 38 & 38 \\
Pelvic Discomfort & 48 & 48 \\
Headache & 33 & 33 \\
Aches \& Pains & 58 & 58 \\
Premenstrual & 56 & 56 \\
dysmenorrhoea & & \\
\hline
\end{tabular}

Table II shows frequency of various psychological symptoms with mood swings (62\%) being the most common symptom. Regarding the frequency of behavioral symptoms loss of concentration was present in $45 \%$ followed by absenteeism in $23 \%$.

Table II Frequencr of Psychological Symptoms $(\mathrm{n}=100)$

\begin{tabular}{lcl}
\hline Symptoms & $\mathrm{n}$ & $\%$ age \\
\hline Tension & 50 & 50 \\
Anxiety & 54 & 54 \\
Tiredness \& fatigue & 32 & 32 \\
Sleep Disturbance & 30 & 30 \\
Craving for sweet food & 12 & 12 \\
Mood Swings & 68 & 68 \\
\hline
\end{tabular}

\section{Discussion:}

This study showed a high (66.66\%) prevalence of PMS with aches \& panes, pre-menstrual dysmenorrhoea, anxiety and mood swings as symptoms reported by majority of girls. A study conducted in America ${ }^{5}$ showed 76 prevalence of PMS with a very high frequency of psychological symptoms. In a study conducted at Karachi in various socio-economic groups' prevalence of FMS was found to be $33 \%{ }^{6}$. This low incidence maybe duo to difference in the study population as our subjects was medical students and they understood the symptoms clearly. In our society topics like PMS and menstruation are rarely discussed openly and people feel embarrassed to discuss the psychological problems. $45 \%$ girls complained of loss of concentration and $23 \%$ had to take leave during 
1. time thus affecting their studies. Treatment of PMS w $w$ th NSAIDS, anxiolytics and hormones may reduce the severity of symptoms and improve the quality of life ${ }^{5}$.

\section{Conclusion:}

PMS is a common problem in young girls. Majority of the girls cannot do their routine work very well during this phase. Teachers, physicians and gynecologists should play a role by making young girls aware about the symptoms of PMS and various treatment options so that their quality of life may be improved.

\section{References:}

1. Reid RL \& Yen SS (1981) Pre-menstrual syndrome. Am J Obstet Gynecol 139, 85-104.
2. Freeman E (1992) PMS: recent views and treatments. Women's psychiatr health 2, 3-5

3. Steiner M: Pre-menstrual syndrome and pre-menstrual dysphoric disorder. J Psychiatry Neuro 2000; 25:459

4. Frank RT (1991) The hormonal causes of premenstrual tension. Arch Neurol Psychiatr 26, 1053-7.

5. Faratein B, O'Brien (1994) Pre-menstrual syndrome, weight, abdominal swelling, and perceived body image. Am J Obstet Gynaecol 150, 200-4

6. Shershah S, Morrison JJ, Jaffery S (1991), Premenstrual Syndrome in Pakistani women J Pak Med Assoc, 1991 May; 41(5); 101-3. 